\title{
Correlation between endoscopic macroscopic type and invasion depth for early esophagogastric junction adenocarcinomas
}

\author{
Ichiro Oda $\cdot$ Seiichiro Abe $\cdot$ Chika Kusano $\cdot$ Haruhisa Suzuki $\cdot$ \\ Satoru Nonaka $\cdot$ Shigetaka Yoshinaga $\cdot$ Hirokazu Taniguchi $\cdot$ \\ Tadakazu Shimoda $\cdot$ Takuji Gotoda
}

Received: 9 March 2010/Accepted: 18 August 2010/Published online: 28 January 2011

(c) The International Gastric Cancer Association and The Japanese Gastric Cancer Association 2011

\begin{abstract}
Background Although correlations between endoscopic macroscopic type and tumor depth have been reported for superficial esophageal squamous cell carcinoma and early gastric and early colorectal adenocarcinomas, there is no published study investigating the correlation between endoscopic macroscopic type and invasion depth for mucosal (M) and submucosal (SM) adenocarcinomas located at the esophagogastric junction (EGJ). We decided to analyze, therefore, the relationship between endoscopic macroscopic type and tumor depth for such cancers.

Methods We retrospectively reviewed 73 early EGJ adenocarcinomas $(\mathrm{M} / \mathrm{SM}=33 / 40$; differentiated/undifferentiated type $=70 / 3)$ in 73 consecutive patients treated endoscopically and/or surgically between January 2000 and December 2008. The mean age of the patients was 63.9 years (range 37-85 years) and the male/female ratio was 62:11. EGJ adenocarcinoma was defined as junctional carcinoma (type II) according to the Siewert classification.
\end{abstract}

I. Oda $(\bowtie) \cdot$ S. Abe $\cdot$ C. Kusano - H. Suzuki - S. Nonaka ·

S. Yoshinaga $\cdot$ T. Gotoda

Endoscopy Division, National Cancer Center Hospital,

5-1-1 Tsukiji, Chuo-ku, Tokyo 104-0045, Japan

e-mail: ioda@ncc.go.jp

C. Kusano - T. Gotoda

Department of Gastroenterology and Hepatology,

National Center for Global Health and Medicine,

Tokyo, Japan

H. Taniguchi

Pathology Division, National Cancer Center Hospital,

Tokyo, Japan

T. Shimoda

Center for Cancer Control and Information Services,

National Cancer Center, Tokyo, Japan
Results We found polypoid type lesions (0-I) in 14 patients, non-polypoid type without mixed type (0-IIa, 0 -IIb, or 0 -IIc) in 39 , and mixed type (0-IIa + IIc or 0 -IIc + IIa) in 20 patients. Non-polypoid type without mixed type (31\%; 12/39) lesions had a significantly lower risk for SM invasion compared to polypoid type $(79 \% ; 11 / 14 ; p<0.01)$ and mixed type $(85 \% ; 17 / 20 ; p<0.01)$ lesions. In polypoid type lesions, the risk of SM invasion was significantly lower for the pedunculated subtype ( 0 -Ip) than for the sessile subtype (0-Is) lesions ( $0 \% ; 0 / 2$ vs. 92\%; 11/12; $p<0.05)$. M lesions (mean size $14.5 \pm 7.5 \mathrm{~mm}$ ) were significantly smaller than SM lesions $(24.5 \pm 7.7 \mathrm{~mm} ; p<0.01)$.

Conclusions Determination of endoscopic macroscopic type may be useful in accurately diagnosing early EGJ adenocarcinoma invasion depth.

Keywords Esophagogastric junction - Adenocarcinoma Endoscopic macroscopic type $\cdot$ Depth of invasion

\section{Introduction}

Accurate endoscopic diagnosis of invasion depth for gastrointestinal cancer is essential for making the proper decision on treatment strategy. The use of endoscopic resection in treating early gastrointestinal cancer has become more widespread recently. As a result, the differential endoscopic diagnosis of mucosal (M) and submucosal (SM) depth of invasion has become increasingly important for determining the indications for endoscopic resection [1-3].

Endoscopy examination is the primary modality for diagnosing gastrointestinal cancer and is also helpful in diagnosing invasion depth. Correlations between endoscopic macroscopic type and invasion depth have been 


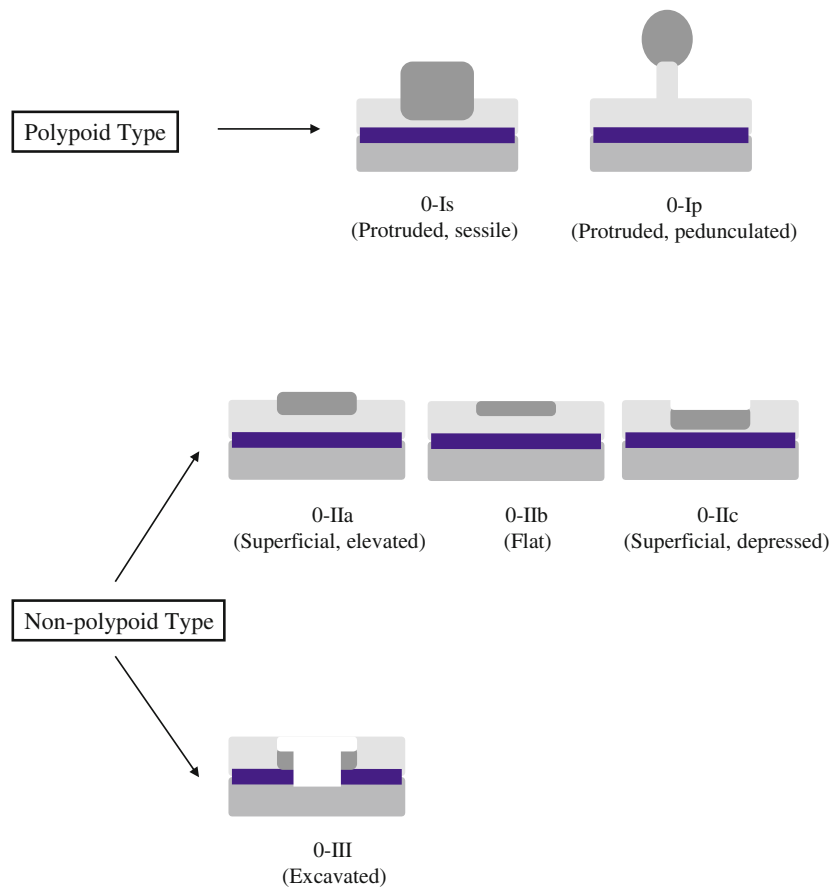

Fig. 1 Classification of endoscopic macroscopic types of early esophagogastric junction adenocarcinomas

reported for superficial esophageal squamous cell carcinoma and early gastric and early colorectal adenocarcinomas in The Paris endoscopic classification of superficial neoplastic lesions [4], and in an even more recent evaluation, of endoscopic macroscopic types in early Barrett's neoplasia, such correlations have also been reported [5]. There has been no previously published study, however, investigating the correlation between endoscopic macroscopic type and invasion depth for $\mathrm{M}$ and SM adenocarcinomas located at the esophagogastric junction (EGJ). The intention of this study was to clarify the relationship between endoscopic macroscopic type and invasion depth for such early EGJ adenocarcinomas.

\section{Patients and methods}

A total of 73 early EGJ adenocarcinomas in 73 consecutive patients treated endoscopically and/or surgically between January 2000 and December 2008 at the National Cancer Center Hospital in Tokyo, Japan, were retrospectively analyzed in this study. EGJ adenocarcinoma was defined as a junctional carcinoma (type II) according to the Siewert classification [6]. An upper gastrointestinal endoscopy examination was performed on each patient before treatment.

We reviewed the clinical records and endoscopic and pathological reports for every patient and analyzed the relationships between invasion depth of early EGJ
Table 1 Clinicopathological findings of 73 patients with esophagogastric junction adenocarcinoma

\begin{tabular}{|c|c|}
\hline Age, mean $\pm \mathrm{SD}$ (years) & $63.9 \pm 12.0$ \\
\hline \multicolumn{2}{|l|}{$\operatorname{Sex}(\%)$} \\
\hline Male & $62(85)$ \\
\hline Female & $11(15)$ \\
\hline \multicolumn{2}{|l|}{ Invasion depth (\%) } \\
\hline Mucosal & $33(45)$ \\
\hline Submucosal & $40(55)$ \\
\hline \multicolumn{2}{|l|}{ Initial treatment $(\%)$} \\
\hline Endoscopic resection & $40(55)$ \\
\hline Surgical resection & $33(45)$ \\
\hline \multicolumn{2}{|l|}{ Histological type (\%) } \\
\hline Differentiated type & $70(96)$ \\
\hline Undifferentiated type & $3(4)$ \\
\hline \multicolumn{2}{|l|}{ Histological finding (\%) } \\
\hline Barrett's cancer & $42(58)$ \\
\hline Non-Barrett's cancer & $31(42)$ \\
\hline \multicolumn{2}{|l|}{ Tumor location, quarter (\%) } \\
\hline 12:01-3 o'clock & $50(68)$ \\
\hline 3:01-6 o'clock & $10(14)$ \\
\hline 6:01-9 o'clock & $3(4)$ \\
\hline 9:01-12 o'clock & $10(14)$ \\
\hline Tumor size, mean $\pm \mathrm{SD}(\mathrm{mm})$ & $20.0 \pm 9.1$ \\
\hline \multicolumn{2}{|l|}{ Endoscopic macroscopic type (\%) } \\
\hline $0-\mathrm{I}$ & $14(19)$ \\
\hline 0-IIa & $8(11)$ \\
\hline 0-IIb & $1(1)$ \\
\hline 0-IIc & $30(41)$ \\
\hline 0-IIa + IIc & $17(23)$ \\
\hline $0-\mathrm{II} c+\mathrm{IIa}$ & $3(4)$ \\
\hline 0-III & $0(0)$ \\
\hline
\end{tabular}

$S D$ Standard deviation

adenocarcinomas and the following clinicopathological findings: age, gender, initial treatment, histological type, histological findings with regard to a diagnosis of Barrett's cancer, center of tumor location, tumor size, and endoscopic macroscopic type.

Invasion depth for early EGJ adenocarcinomas was divided into $\mathrm{M}$ and SM and initial treatment was divided into endoscopic resection and surgical resection. Histological type was diagnosed based on the predominant tumor pattern in the $M$ layer and then divided into two types: differentiated type and undifferentiated type, according to the Japanese classification of gastric carcinoma [7]. The histological findings with regard to a diagnosis of Barrett's cancer were classified as Barrett's cancer and non-Barrett's cancer, with Barrett's cancer diagnosed whenever a tumor was continuously located on Barrett's esophagus. The center of tumor location was divided into quarters (12:013:00, 3:01-6:00, 6:01-9:00, and 9:01-12:00 o'clock), using 
Table 2 Correlation between clinicopathological findings and invasion depth
SD Standard deviation, NS not significant

* Significantly different from non-polypoid type without mixed type

\begin{tabular}{|c|c|c|c|}
\hline & \multicolumn{2}{|c|}{ Invasion depth } & \multirow[t]{2}{*}{$p$ value } \\
\hline & $\begin{array}{l}\text { Mucosal } \\
(n=33)\end{array}$ & $\begin{array}{l}\text { Submucosal } \\
(n=40)\end{array}$ & \\
\hline Age, mean \pm SD (years) & $63.3 \pm 11.5$ & $64.3 \pm 12.5$ & NS \\
\hline \multicolumn{4}{|l|}{$\operatorname{Sex}(\%)$} \\
\hline Male & $28(45)$ & $34(55)$ & \multirow[t]{2}{*}{ NS } \\
\hline Female & $5(45)$ & $6(55)$ & \\
\hline \multicolumn{4}{|l|}{ Histological type (\%) } \\
\hline Differentiated type & $33(47)$ & $37(53)$ & \multirow[t]{2}{*}{ NS } \\
\hline Undifferentiated type & $0(0)$ & $3(100)$ & \\
\hline \multicolumn{4}{|l|}{ Histological findings (\%) } \\
\hline Barrett's cancer & $23(55)$ & $19(45)$ & \multirow[t]{2}{*}{ NS } \\
\hline Non-Barrett's cancer & $10(32)$ & $21(68)$ & \\
\hline \multicolumn{4}{|l|}{ Tumor location, half (\%) } \\
\hline 12:01-6 o'clock & $28(47)$ & $32(53)$ & \multirow[t]{2}{*}{ NS } \\
\hline 6:01-12 o’clock & $5(38)$ & $8(62)$ & \\
\hline Tumor size, mean $\pm \mathrm{SD}(\mathrm{mm})$ & $14.5 \pm 7.5$ & $24.5 \pm 7.7$ & $<0.01$ \\
\hline \multicolumn{4}{|l|}{ Endoscopic macroscopic type (\%) } \\
\hline Polypoid type (0-I) & $3(21)$ & $11(79)$ & \multirow[t]{2}{*}{$<0.01 *$} \\
\hline $\begin{array}{l}\text { Non-polypoid type without mixed type } \\
\text { (0-IIa, } 0 \text {-IIb or } 0 \text {-IIc) }\end{array}$ & $27(69)$ & $12(31)$ & \\
\hline Mixed type $(0-$ IIa + IIc or 0 -IIc + IIa $)$ & $3(15)$ & $17(85)$ & $<0.01^{*}$ \\
\hline
\end{tabular}

the forward endoscopic EGJ view. Tumor size was defined as the length of the major axis. Endoscopic macroscopic type was classified based on the Paris classification and divided into polypoid (0-I) and non-polypoid (0-IIa, 0-IIb, 0-IIc and 0-III) types (Fig. 1) [4]. A mixed type was diagnosed whenever a lesion consisted of at least two distinct endoscopic macroscopic types. Polypoid type lesions were then subdivided into sessile (0-Is) and pedunculated (0-Ip) subtype lesions.

Data were analyzed using the $\chi^{2}$ test, Fisher's exact test, or Student's $t$ test as appropriate. Value differences in which $p<0.05$ were considered statistically significant.

\section{Results}

Clinicopathological findings are shown in Table 1. The mean age \pm standard deviation (SD) of the patients was $63.9 \pm 12.0$ years and the male/female ratio was 5.64 (62:11). Relationships between clinicopathological findings and invasion depth are shown in Table 2. M lesions (mean size $14.5 \pm 7.5 \mathrm{~mm}$ ) were significantly smaller than SM lesions $(24.5 \pm 7.7 \mathrm{~mm} ; p<0.01)$. Non-polypoid type without mixed type (0-IIa, 0 -IIb or 0 -IIc) lesions had a significantly lower risk for SM invasion than polypoid type (0-I) and mixed type (0-IIa + IIc or 0-IIc + IIa) lesions (Table 2; see images in Figs. 2, 3, 4). When polypoid type lesions were subdivided into sessile (0-Is) and pedunculated
(0-Ip) subtypes, the risk of SM invasion was significantly lower for the pedunculated subtype than for the sessile subtype $(0 \%$; $0 / 2$ vs. $92 \%, 11 / 12 ; p<0.05)$ (see images in Figs. 4, 5).

\section{Discussion}

There has been a dramatic increase in the incidence of EGJ adenocarcinomas in the United States and other Western countries over the past two decades [8-12]. It has also been reported from a large referral center in Japan that the proportion of EGJ adenocarcinomas among all gastric adenocarcinomas detected in Japanese patients has been increasing in recent years [13].

Remarkable progress has been made during the past decade in the development and refinement of endoscopic resection methods, from conventional endoscopic mucosal resection (EMR) to endoscopic submucosal dissection (ESD) [14-20], which has been applied to early EGJ adenocarcinomas [21]. Consequently, accurate differential endoscopic diagnosis of M and SM invasion depth in early EGJ adenocarcinomas has become more important for determining the indications for such procedures.

Endoscopic ultrasonography (EUS) is one of the current modalities used for diagnosing tumor invasion depth. Using conventional EUS (7.5 MHz), advanced T3/T4 carcinomas can be distinguished from T1/T2 carcinomas in 

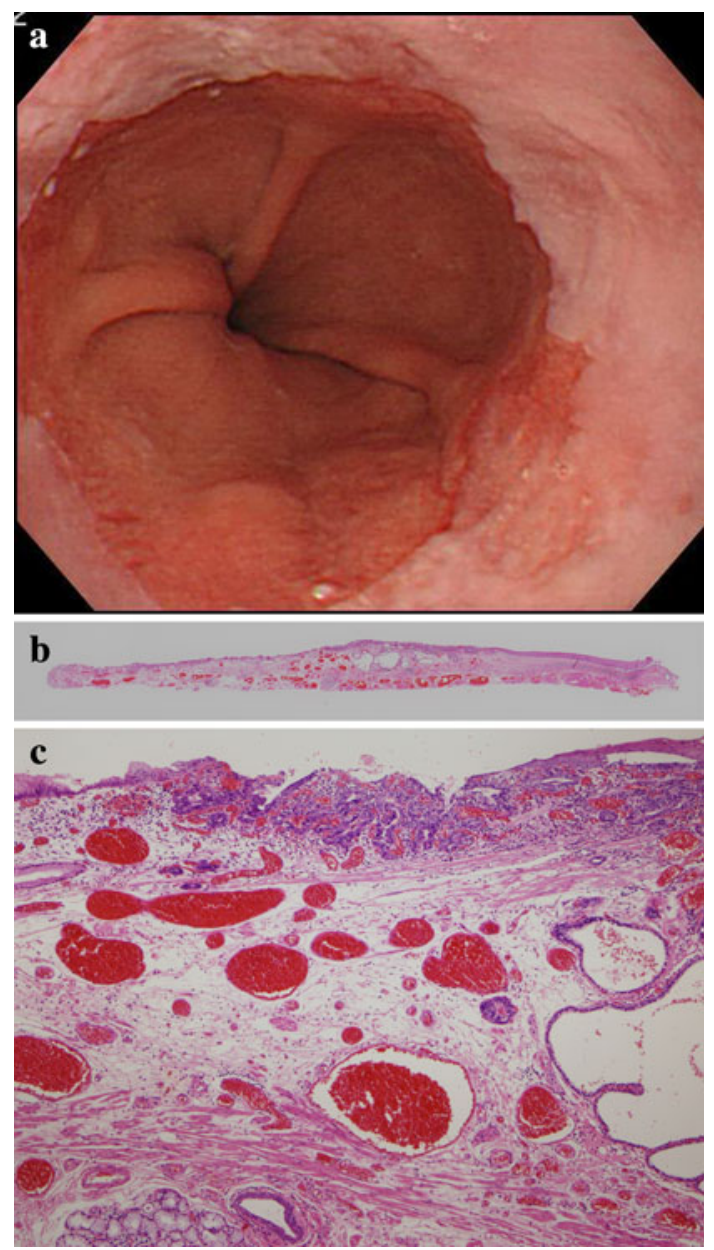

Fig. 2 a Endoscopic image reveals a non-polypoid type without mixed type, slightly depressed (0-IIc) lesion at the esophagogastric junction (EGJ). b, c Histological features of the resected specimen indicate a well-differentiated adenocarcinoma confined to the mucosal layer that had spread to the subepithelial layer of the esophagus (b H\&E, panoramic view), (c H\&E, $\times 40)$

more than $80 \%$ of cases; however, accurate differentiation between $M$ and SM invasion depth is difficult [22-24]. EUS using a miniprobe $(20 \mathrm{MHz})$ has reportedly demonstrated a high diagnostic accuracy of approximately $80 \%$ for differentiating between $\mathrm{M}$ and SM early EGJ adenocarcinomas. There was no significant difference, however, between EUS diagnostic accuracy and that of high-resolution video endoscopy [23]. Consequently, endoscopy can also be helpful in diagnosing invasion depth, but such diagnosis is subjective in nature so there is a need for objective criteria.

In the present study, we analyzed the relationship between the invasion depth of early EGJ adenocarcinomas and relevant clinicopathological findings, including endoscopic macroscopic type. We found that M lesions were
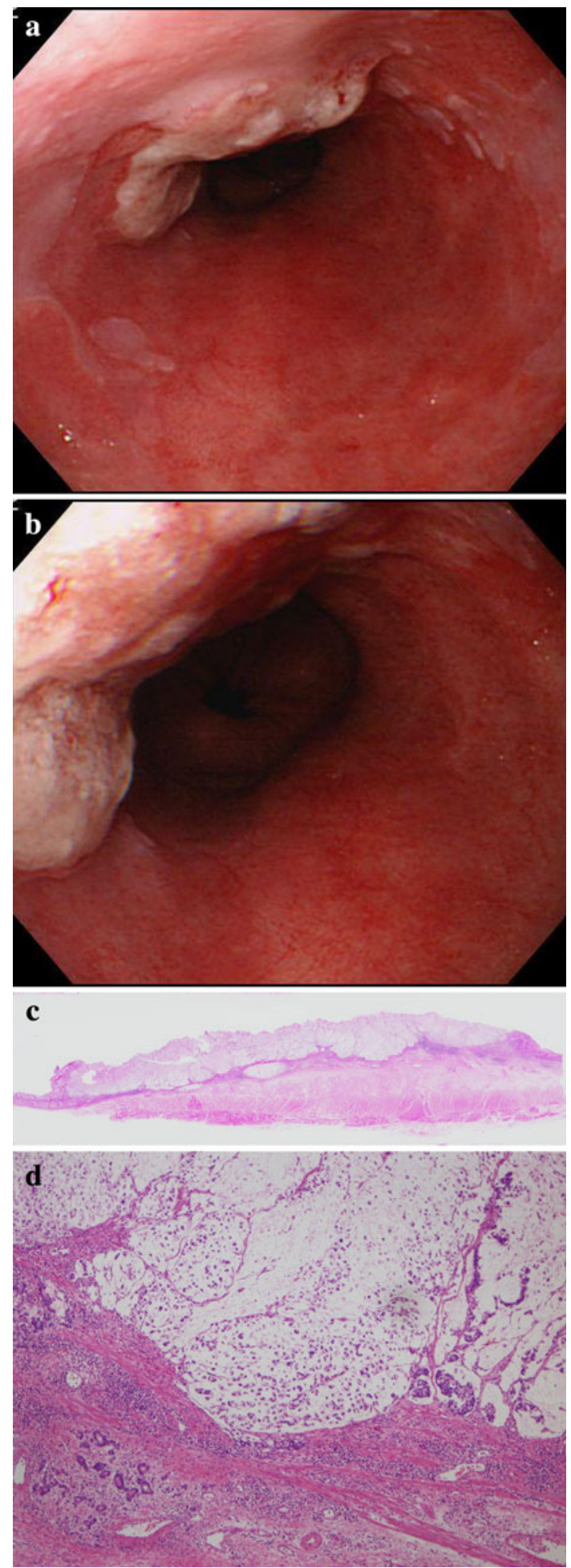

Fig. 3 a, b Endoscopic images reveal a mixed type, elevated lesion with a central depression (0-IIa + IIc) at the EGJ. c, d Histological features of the resected specimen indicate a mucinous adenocarcinoma in the mucosal layer and a poorly differentiated adenocarcinoma that had invaded the submucosal layer (c H\&E, panoramic view), (d H\&E, × 100) 

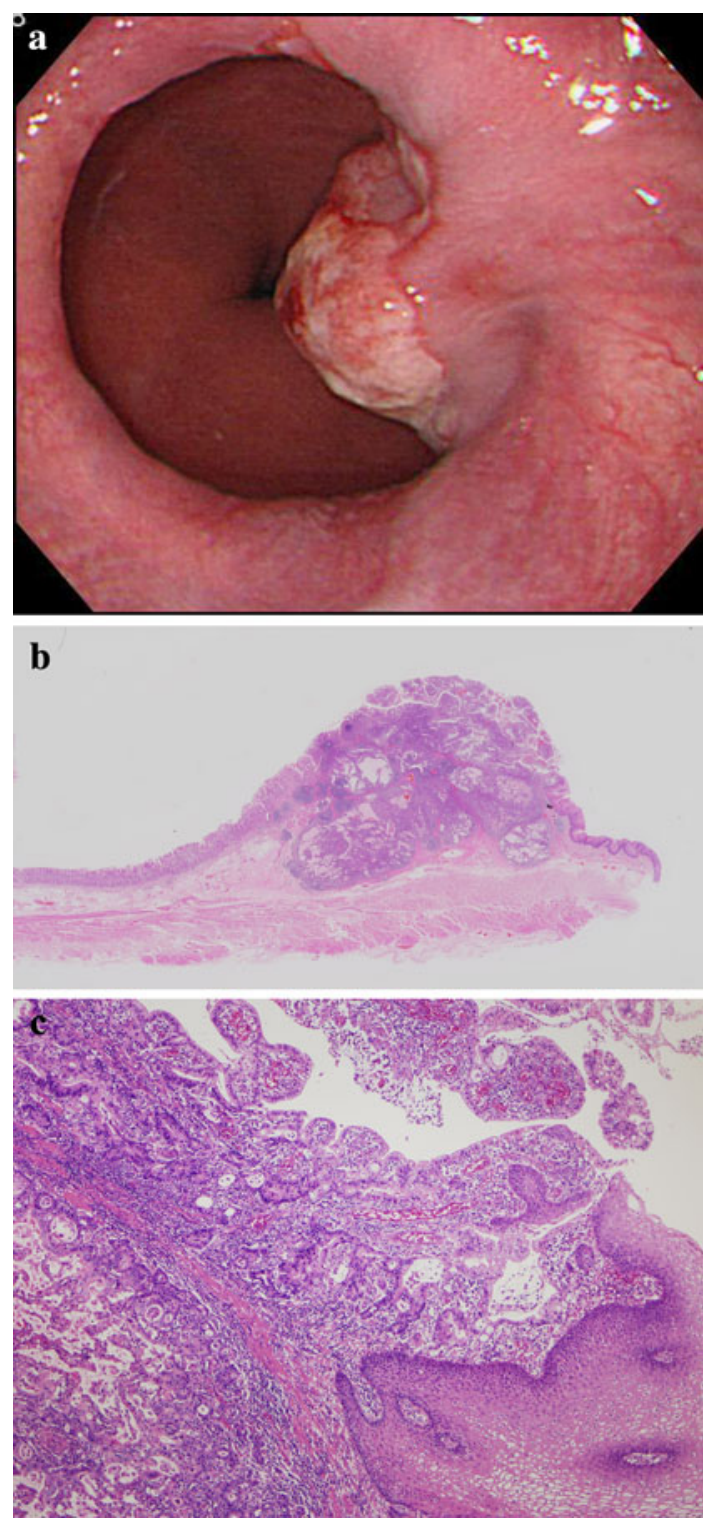

Fig. 4 a Endoscopic image reveals a polypoid type, sessile subtype (0-Is) lesion at the EGJ. b, c Histological features of the resected specimen indicate a well-differentiated adenocarcinoma that had invaded the submucosal layer (b H\&E, panoramic view), (c H\&E, $\times 100)$

significantly smaller than SM lesions. Non-polypoid type without mixed type (0-IIa, 0 -IIb or 0 -IIc) lesions had a significantly lower risk for SM invasion compared to polypoid type (0-I) and mixed type (0-IIa + IIc or 0 -IIc + IIa) lesions. In the polypoid type lesions, the risk for SM invasion was significantly lower for the pedunculated subtype (0-Ip) than for the sessile subtype (0-Is) lesions. These results were similar to those in previously published reports of other gastrointestinal neoplasias [4, 5].

One limitation of the present study is that it was a retrospective investigation from a single center, with a
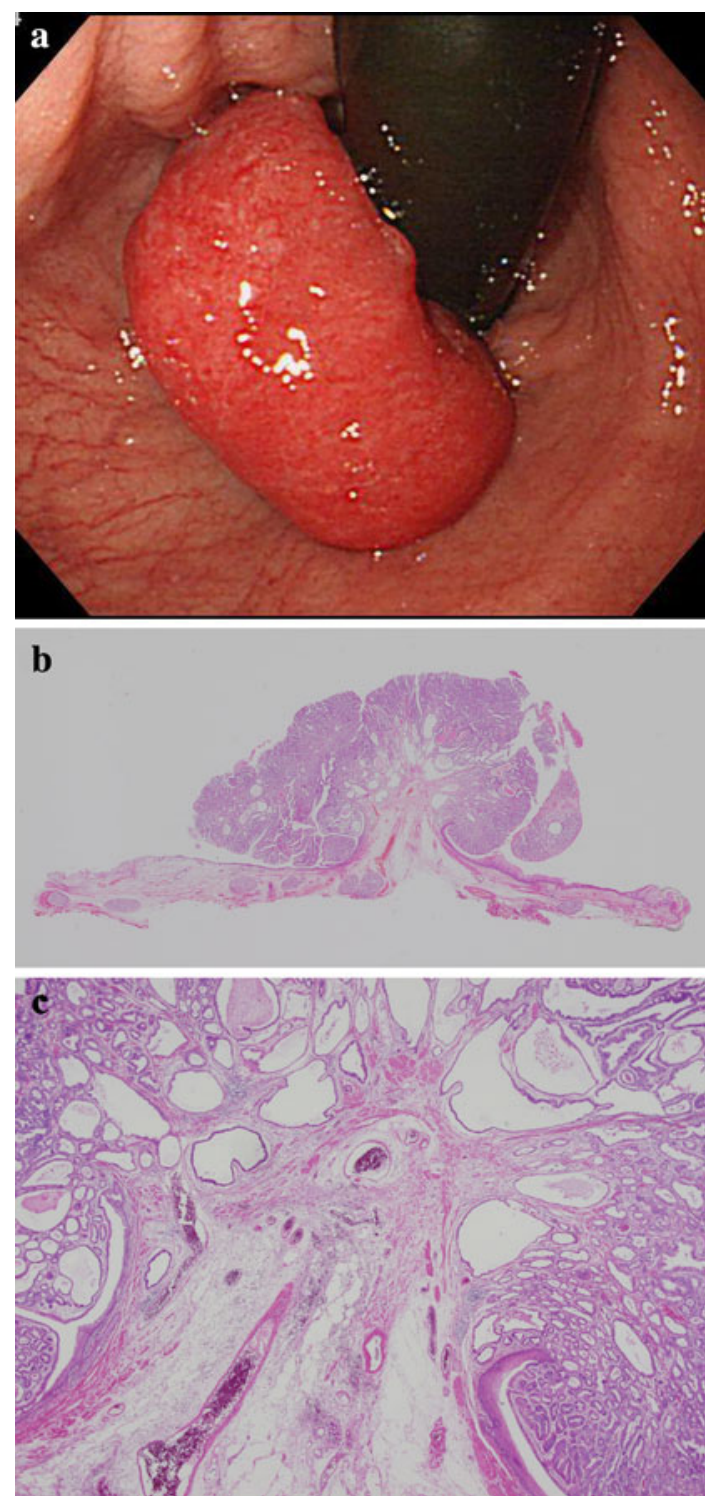

Fig. 5 a Endoscopic image reveals a polypoid type, pedunculated subtype (0-Ip) lesion at the EGJ. b, c Histological features of the resected specimen indicate a well-differentiated adenocarcinoma confined to the mucosal layer (b H\&E, panoramic view), (c H\&E, $\times 100)$

relatively small number of reported cases, so a large prospective study will be needed to confirm our findings on the correlation of endoscopic macroscopic type with invasion depth for early EGJ adenocarcinomas. Another limitation of our study was that invasion depth for early EGJ adenocarcinomas was divided into M and SM, but SM was not further subdivided into SM1 and SM2, because the definition of SM1 for EGJ adenocarcinomas is still undecided at the present time. SM1 for gastric cancer and esophageal cancer is defined as a tumor that invades less than $500 \mu \mathrm{m}$ and less than $200 \mu \mathrm{m}$, respectively, into the submucosa from the muscularis mucosa and is associated with a lower 
risk of lymph-node metastasis compared with SM2 [4]. Additional investigation as to an accurate definition of SM1 and the risk of lymph-node metastasis for EGJ adenocarcinomas is also necessary.

In conclusion, this retrospective study demonstrated that there were certain correlations between endoscopic macroscopic type and invasion depth for early EGJ adenocarcinomas. As a result, determination of endoscopic macroscopic type may be useful in accurately diagnosing invasion depth for EGJ adenocarcinomas.

\section{References}

1. Rembacken BJ, Gotoda T, Fujii T, Axon AT. Endoscopic mucosal resection. Endoscopy. 2001;33:709-18.

2. Soetikno R, Gotoda T, Nakanishi Y, Soehendra N. Endoscopic mucosal resection. Gastrointest Endosc. 2003;57:567-79.

3. Soetikno R, Kaltenbach T, Yeh R, Gotoda T. Endoscopic mucosal resection for early cancers of the upper gastrointestinal tract. J Clin Oncol. 2005;23:4490-8.

4. Participants in the Paris Workshop. The Paris endoscopic classification of superficial neoplastic lesions: esophagus, stomach, and colon. Gastrointest Endosc. 2003;58(Suppl 6):S3-43.

5. Pech O, Gossner L, Manner H, May A, Rabenstein T, Behrens A, et al. Prospective evaluation of the macroscopic types and location of early Barrett's neoplasia in 380 lesions. Endoscopy. 2007;39:588-93.

6. Siewert JR, Stein HJ. Classification of adenocarcinoma of the oesophagogastric junction. Br J Surg. 1998;85:1457-9.

7. Japanese Gastric Cancer Association. Japanese classification of gastric carcinoma. 2nd English ed. Gastric Cancer. 1998;1:10-24.

8. Blot WJ, Devesa SS, Kneller RW, Fraumeni JF Jr. Rising incidence of adenocarcinoma of the esophagus and gastric cardia. JAMA. 1991;265:1287-9.

9. Devesa SS, Blot WJ, Fraumini JF Jr. Changing patterns in the incidence of esophageal and gastric carcinoma in the United States. Cancer. 1998;83:2049-53.

10. Hansson LE, Sparen P, Nyren O. Increasing incidence of both major histological types of esophageal carcinomas among men in Sweden. Int J Cancer. 1993;54:402-7.

11. Pera M, Cameron AJ, Trastek VF, Carpenter HA, Zinsmeister AR. Increasing incidence of adenocarcinoma of the esophagus and esophagogastric junction. Gastroenterology. 1993;104:510-3.
12. Vizcaino AP, Moreno V, Lambert R, Parkin DM. Time trends of both major histologic types of esophageal carcinoma in selected countries. Int J Cancer. 2002;99:860-8.

13. Kusano C, Gotoda T, Khor CJ, Katai H, Kato H, Taniguchi H, et al. Changing trends in the proportion of adenocarcinoma of the esophagogastric junction in a large tertiary referral center in Japan. J Gastroenterol Hepatol. 2008;23:1662-5.

14. Gotoda T, Yamamoto H, Soetikno R. Endoscopic submucosal dissection of early gastric cancer. J Gastroenterol. 2006;41:929-42.

15. Oda I, Gotoda T, Hamanaka H, Eguchi T, Saito Y, Matsuda T, et al. Endoscopic submucosal dissection for early gastric cancer: technical feasibility, operation time and complications from a large consecutive series. Dig Endosc. 2005;17:54-8.

16. Yamamoto H, Kawata H, Sunada K, Sasaki A, Nakazawa K, Miyata T, et al. Successful one-piece resection of large superficial tumors in the stomach and colon using sodium hyaluronate and small-caliber-tip transparent hood. Endoscopy. 2003;35:690-4.

17. Oyama T, Kikuchi Y. Aggressive endoscopic mucosal resection in the upper GI tract-Hook knife EMR method. Minim Invasive Ther Allied Technol. 2002;11:291-5.

18. Fujishiro M, Yahagi N, Nakamura M, Kakushima N, Kodashima $\mathrm{S}$, Ono S, et al. Successful outcomes of a novel endoscopic treatment for GI tumors: endoscopic submucosal dissection with a mixture of high-molecular-weight hyaluronic acid, glycerin, and sugar. Gastrointest Endosc. 2006;63:243-9.

19. Oda I, Saito D, Tada M, Iishi H, Tanabe S, Oyama T, et al. A multicenter retrospective study of endoscopic resection for early gastric cancer. Gastric Cancer. 2006;9:262-70.

20. Oda I, Gotoda T. Remarkable progress in endoscopic resection of early gastric cancer. J Gastroenterol Hepatol. 2009;24:1313-4.

21. Yoshinaga S, Gotoda T, Kusano C, Oda I, Nakamura K, Takayanagi R. Clinical impact of endoscopic submucosal dissection (ESD) for superficial adenocarcinoma located at the esophagogastric junction (EGJ). Gastrointest Endosc. 2008;67:202-9.

22. Kelly S, Harris KM, Berry E, Hutton J, Roderick P, Cullingworth $\mathrm{J}$, et al. A systematic review of the staging performance of endoscopic ultrasound in gastro-oesophageal carcinoma. Gut. 2001;49:534-9.

23. May A, Gunter E, Roth F, Gossner L, Stolte M, Vieth M, et al. Accuracy of staging in early oesophageal cancer using high resolution endoscopy and high resolution endosonography: a comparative, prospective, and blinded trial. Gut. 2004;53:634-40.

24. Hiele M, De Leyn P, Schurmans P, Lerut A, Huys S, Geboes K, et al. Relation between endoscopic ultrasound findings and outcome of patients with tumors of the esophagus or esophagogastric junction. Gastrointest Endosc. 1997;45:381-6. 